\title{
De pace fidei: de la libertad a la tolerancia*
}

\author{
Enzo Solari \\ PONTIFICIA UNIVERSIDAD CATÓLICA DE VALPARAÍSO
}

De pace fidei (La paz de la fe o La paz en la fe = DPF), la obra del librepensador cardenal Nicolás de Cusa, es todo un clásico, tanto en el sentido de su explosiva significatividad como en el de su rica y variada influencia. De ella debe decirse lo que decía Goethe cuando elogiaba a Molière: "pues nosotros, hombres pequeños, no somos capaces de atesorar la grandeza de semejantes cosas, y por ello siempre tenemos que volver a ellas de tiempo en tiempo para refrescar en nosotros mismos tales impresiones» ${ }^{1}$.

Como se sabe, DPF funge de locus classicus dentro de la historia de la tolerancia. Sería, se dice, un antecedente medieval -compuesto rápidamente en 1453 poco después de la caída de Constantinopla en manos turcas- de una idea propiamente moderna. Hay aquí un posible malentendido. A proponer algunos criterios de juicio para aclararlo y mejor encarar esta cuestión se dedican las páginas que siguen, cosa que se realiza extrayendo el argumento central del libro, revisando luego algunas interpretaciones recientes del mismo y ofreciendo finalmente un ramillete de cuestiones abiertas por él, todo lo cual permitirá entender mejor en

Este texto es parte de una investigación financiada por el Concurso Fondecyt de Iniciación a la Investigación ( ${ }^{\circ}$ 11090205): Raices medievales de la tolerancia. Las contribuciones de Abelardo, Llull, Tomás y el Cusano. Para escribirlo, además, el autor se ha beneficiado de una beca B de Stipendienwerk Lateinamerika-Deutschland que financió su estadía (entre junio y agosto de 2010) en el Grabmann-Institut de la Facultad de Teología Católica de la Ludwig-Maximilian Universität de München (donde tuvo como amable huésped al Prof. Dr. Martin Thurner).

1 «Denn wir kleinen Menschen sind nicht fähig, die Grösse solcher Dinge in uns zu bewahren, und wir müssen daher von Zeit zu Zeit immer dahin zurückkehren, um solche Eindrücke in uns aufzufrischen»: J. P. Eckermann, Gespräche mit Goethe in den letzten Jahren seines Lebens 1823-1832 (Berlin, Aufbau-Verlag 1956), 212. 
qué sentido la del Cusano es una versión medieval de la tolerancia en la que relucen motivos también modernos ${ }^{2}$.

\section{El ARgumento Del teXto}

Conviene, ante todo, destacar tan claramente como sea posible las articulaciones cruciales del argumento que recorre DPF, cuya misma brevedad se diría que las vuelve más apretadas.

1.1. Todo comienza con cierto varón, probablemente Nicolás, quien, ante la divulgación de las crueldades del rey turco (saevissime acta) en la toma de Constantinopla (ciudad en la que ya había estado), se llena de celo divino, en una oratio suplica al Dios creador de todas las cosas que con su piedad modere esa sevicia persecutoria ${ }^{3}$ y, luego de una continuada meditación, tiene una visio, según la cual la pericia de unos pocos sabios, conocedores de las diferencias religiosas que hay en el orbe, puede permitir (reperiri) la concordia interreligiosa y asegurar una paz perpetua convenientemente y de acuerdo a la verdad, ac veraci $i^{4}$. El varón, después, escribe la visión para que los responsables de estos asuntos tomen nota 5 .

De acuerdo con dicha visión, no hay multitud sin diversidad y, entre los hombres, el ocio lleva a la libertad y esta al conocimiento (notitia) propio, según el cual -es la teología negativa del Cusano- Deus est Deus absconditus ${ }^{6}$. Dios pone al frente de su pueblo a reyes y videntes, es decir, envía profetas y maestros a las naciones, quienes instituyen culto, leyes e instrucción para el pueblo rudo. Este cree que los profetas establecieron estas cosas hablando cara a cara (facie ad faciem) con Dios, de modo que cree escuchar a Dios cuando los escucha a ellos ${ }^{7}$. Es peculiar del hombre terreno considerar naturales y verdaderas a las costumbres antiguas. De

2 Aquí se detallan y continúan argumentos meramente incoados en Enzo Solari, E. SOLARI, «Contornos de la tolerancia medieval», en curso de publicación en Ideas y valores. Revista colombiana de filosofía.

3 Vid. DPF, h VII, c. I, n. 1, p. 1, 6-7 (remitiré de aquí en adelante también a la buena traducción española de V. SAnZ: N. De Cusa, La paz de la fe. Carta a Juan de Segovia (Madrid, Tecnos 1998), 3.

4 Vid. DPF, h VII, c. I, n. 1, p. 1, 8-9 - p. 2, 5 (trad. esp. pp. 3-4).

5 Vid. DPF, h VII, c. I, n. 1, p. 4, 5-7 (trad. esp. p. 4).

6 Vid. DPF, h VII, c. I, n. 4, p. 5, 11-12, 14-16 y 17 (trad. esp. p. 5).

7 Vid. DPF, h VII, c. I, n. 4, p. 5, 18, p. 6, 3 (trad. esp. pp. 5-6). 
ahí proceden las disensiones que sobrevienen cuando cada comunidad prefiere su propia fe sobre las demás ${ }^{8}$.

El hombre, viviente y existente, cuando busca (quaerit) vivir (vivere) y ser (esse), busca a Dios a través de diferentes ritos y con distintos nombres, y puede comprehenderlo si y solo si se hace visible; en cambio, lo abandona si y solo si lo ignora'. Dios, poder infinito (infinita virtus) que da la vida y el ser, sumo bien que se apetece cada vez que algo se apetece, verdad de toda verdad, el único venerado en todo lo que se adora, buscado a través de diferentes ritos y con distintos nombres, es siempre desconocido (incognitus) e inefable (ineffabilis), puede hacerse comprehensible y pregustarse si y solo si se hace visible, propicio y de rostro manifiesto ${ }^{10}$. Dios no es nada creado. Por ello no hay proporción ninguna (nulla proportio) desde lo finito hacia lo infinito ${ }^{11}$.

Si Dios se revela propiciamente, terminarán guerras, odios y males: «y todos conocerán cómo no hay sino una religión en la diversidad de los ritos (et cognoscent omnes quomodo non est nisi religio una in rituum varietate)». Puede convenir o no ser posible suprimir la diversidad ritual. En todo caso la diversidad puede ayudar a acrecentar la devoción. Sin embargo, hay un Dios y por ende una religión, un solo culto de latría, unus latriae cultus. Nicolás es parte del «nosotros (nos)», los enviados o comisarios, los custodios del pueblo de Dios que le suplica piedad y perdón ${ }^{12}$.

Dice el Verbo que el Padre no puede hacer más. Pero que, para evitar errores y hacer que la verdad una luzca continuamente (continue elucescat), esa única verdad hará que toda diversidad de religiones sea conducida (perducetur) a una fe ortodoxa ${ }^{13}$. Ordena entonces el Rey a cada ángel que encabeza una nación y lengua hacer comparecer ante el Verbo a un hombre conspicuo. A estos hombres, casi raptados en éxtasis, les dice el Verbo: el sufrimiento que causa la diversidad de religiones es oído por Dios. Las persecuciones cometidas o padecidas provocan la

\footnotetext{
8 Vid. DPF, h VII, c. I, n. 4, p. 6, 4-8 (trad. esp. p. 6).

9 Vid. DPF, h VII, c. I, n. 5, p. 6, 9 - p. 7, 8 (trad. esp., p. 5).

10 Vid. DPF, h VII, c. I, n. 5, p. 6, 9 - p. 7, 7 (trad. esp., p. 5).

11 Vid. DPF, h VII, c. I, n. 5, p. 6, 17 - p. 7, 2 (trad. esp., p. 6).

12 Vid. DPF, h VII, c. I, n. 6, p. 7, 9-12 y 14-19 (trad. esp., p. 7).

13 Vid. DPF, h VII, c. III, n. 8, p. 9, 16 - p. 10, 4-6 (trad. esp. pp. 8-9).
} 
compasión de Dios. Mediante un consenso común de todos los hombres (communi omnium hominum consensu), la diversidad de religiones ha de ser concordemente reducida (concorditer reduci) a una única inviolable. Semejante reducción consensuada de la diversidad a la unidad religiosa tiene lugar en Jerusalén ${ }^{14}$.

1.2. En este punto empieza la plural conversación (de la que participan en total diecisiete sabios). El primero que entra en escena es el Graecus, quien afirma que solo Dios puede hacer que la diversidad religiosa sea conducida (conducatur) a la paz concordante. Pero si las naciones difícilmente renuncian a su fe, ¿cómo puede introducirse la unidad? Según el Verbo, hay una única fe presupuesta por doquier. Todos los dialogantes aquí presentes, prosigue, son sabios o, al menos, amantes de la sabiduría, filósofos. Por ello, todos presuponen la sabiduría. Y como antes que toda pluralidad está la unidad, por eso antes que las sabidurías está la sabiduría ${ }^{15}$. El griego y el Verbo concuerdan en que hay una sabiduría simplicísima, invisible, que excede todas las cosas (omnia excedere), y por cuya participación muchos son sabios (cuius participatione sunt multi sapientes) ${ }^{16}$. Para el griego, de los órganos y los sentidos se asciende al espíritu racional, que es una imagen próxima (propinqua ymagine) de la eterna sabiduría, como la verdad en una semejanza próxima (ut veritas in propinqua similitudine ${ }^{17}$. La relucencia de la sabiduría accede más y más a la verdad por una vehemente conversión del espíritu. Eso sí: la absoluta sabiduría nunca se alcanza en otra cosa (in alio); por eso siempre es alimento (cibus) intelectual perpetuo y sin deficiencia. A lo que el Verbo dice: todos ustedes, en medio de diversas religiones, presuponen (praesupponitis) una única sabiduría ${ }^{18}$.

1.3. Más adelante, un Syrus coge el testigo y afirma que desde algunos presupuestos puede hallarse la concordia en cualquier secta. Para Pedro, casi todas las religiones - las tres monoteístas y otras- afirman la fe en la resurrección a una vida eterna ${ }^{19}$. Ambos, Pedro y el sirio, admiten

14 Vid. DPF, h VII, c. III, n. 9, p. 10, 7-22 (trad. esp. p. 9).

15 Vid. DPF, h VII, c. IV, n. 11, p. 11, 4-14, 16-17 y 19-21 (trad. esp., p. 10).

16 Vid. DPF, h VII, c. IV, n. 11, p. 12, 1-11 (trad. esp. pp. 10-11).

17 Vid. DPF, h VII, c. IV, n. 12, p. 12, 12 - p. 13, 2 (trad. esp. p. 11).

18 Vid. DPF, h VII, c. IV, n. 12, p. 13, 2-8 y 10-12 (trad. esp. pp. 11-12).

19 Vid. DPF, h VII, c. XIII, n. 42, p. 39, 17 y p. 40, 4-7 (trad. esp. p. 35). 
que si es así, entonces creen en la encarnación, que es condición de la resurrección de los hombres ${ }^{20}$. Pedro añade que las promesas hechas a los judíos son confirmadas en la fe del Mesías. El sirio pregunta entonces por las otras sectas, respondiéndole Pedro que si todo hombre busca ser feliz, si solo se puede ser últimamente feliz en la vida eterna -en unión con la inmortal vida divina- y si tales cosas solo son posibles en Cristo como mediador entre la divinidad y la humanidad, entonces Cristo es presupuesto (praesupponitur) por todo el que busca la felicidad última ${ }^{21}$. Convencido, el sirio acepta que sí que es necesaria esa presuposición. Además, dice, coincide con lo que es el origen de la religión: ese deseo innato (connato) de la felicidad en el que no cabe decepción. Pero, aceptando todo esto, los judíos dicen que el Mesías aún no ha nacido. Pedro zanja el asunto sumariamente sugiriendo que basta con que árabes, cristianos y otros den este testimonio ${ }^{22}$.

1.4. Luego de otros interlocutores, aparece el Tartarus, también recomendando acabar con la diversidad que genera persecuciones, divisiones, guerras, pero planteando esta pregunta: ¿cómo lograr la unidad con tanta variedad espacial y temporal de ritos (circuncisión, marcas, bautismos, matrimonios, sacrificios, siendo el más rechazado el eucarístico de los cristianos, quienes se comen al quien adoran)?23. Entonces, por encargo del Verbo, Pablo toma la palabra, diciendo que la salvación viene de la fe, no de las obras, como lo muestra Abraham. Las variedades rituales no turban si se considera que son signa sensibilia veritatis fidei: los signos cambian, no lo signatum ${ }^{24}$. Los méritos no salvan, porque si salvaran, la gracia no sería gracia sino algo debido (debitum). La fe salva, hay que creer en la gracia. Dios da lo que quiere a quien quiere (dat cui vult id quod vult) ${ }^{25}$. El tártaro parece aceptar la fe y la ley, pero pregunta si pueden asumirse universalmente ritos como el de la circuncisión. Pablo subraya entonces que no es necesaria la circuncisión para salvarse ${ }^{26}$. Además, desde el punto de vista de la paz, es preferible que los menos

20 Vid. DPF, h VII, c. XIII, n. 43, p. 40, 14- p. 41, 3 (trad. esp. p. 36).

21 Vid. DPF, h VII, c. XIII, n. 44, p. 41, 4-24 (trad. esp. pp. 36-37).

22 Vid. DPF, h VII, c. XIII, n. 45, p. 41, 25 - p. 42, 18 (trad. esp. pp. 37-38).

23 Vid. DPF, h VII, c. XVI, n. 54, p. 50, 14 - p. 51, 9 (trad. esp. p. 46).

24 Vid. DPF, h VII, c. XVI, n. 55, p. 51, 10 - p. 52, 2 (trad. esp. pp. 46-47).

25 Vid. DPF, h VII, c. XVI, n. 55, p. 52, 11-17 (trad. esp. p. 47).

26 Vid. DPF, h VII, c. XVI, n. 60, p. 55, 16 - p. 56, 1 (trad. esp. p. 51). 
(los circuncidados) se adapten a los más, que no a la inversa (salvo que la inversa funcionase excepcionalmente en pro de la paz). Ha de buscarse la paz en la unidad de la fe y la ley, tolerando los ritos de cada cual ${ }^{27}$.

1.5. El Anglicus, hacia el final, pregunta por el matrimonio, el sacerdocio, la confirmación y la unción. Pablo asevera que hay que ser condescendiente con las debilidades humanas, siempre que así no se entorpezca la salvación, pero pretender en todos los casos una conformidad exacta puede turbar la paz. En el matrimonio y sacerdocio es esperable una concordia ${ }^{28}$. El inglés todavía inquiere por ayunos, oficios, abstinencias, oraciones. Pablo le dice que si allí no se alcanza la conformidad pero se salvan la paz y la fe, debe permitirse a las naciones sus propias devociones y ceremonias. La diversidad (diversitate) puede además aumentar la devoción promoviendo una 'sana competencia' entre las naciones ${ }^{29}$.

1.6. Todas estas cosas se discuten con los sabios de las naciones. Luego se traen excelentes libros antiguos (de Marcus Varro y Eusebio) sobre las viejas observancias y la diversidad religiosa. La conclusión es que tal diversidad es más ritual que cultual, pues presupone siempre el culto al único Dios. Termina así la concordia de las religiones en el cielo de la razón. El Rey manda a los sabios de vuelta a sus naciones para que -asesorados por los espíritus de Dios- las conduzcan a la unidad del culto verdadero (ad unitatem veri cultus). Al fin, todos deben confluir en Jerusalén -como centro común- para aceptar la única fe, firmar la paz perpetua y así alabar al creador de todas las $\operatorname{cosas}^{30}$.

1.7. Conviene agregar que, en su (posterior) carta a Juan de Segovia, y a diferencia de (la también posterior) Cribatio Alkorani, Nicolás todavía enfatiza que la agresión militar no es el mejor medio para el cristiano, y que solo la defensa es sin peligro (sine periculo), mientras que por la fuerza puede ser derrotado ${ }^{31}$. Cree que es mejor conferenciar que guerrear. Ante la pregunta de por qué Dios permite las pruebas, responde diciendo que para la vida, para exaltar la fe, para que la iglesia resplandezca

\footnotetext{
Vid. DPF, h VII, c. XVI, n. 60, p. 56, 8-19 (trad. esp. pp. 51-52).

28 Vid. DPF, h VII, c. XIX, n. 67, p. 61, 11-22 (trad. esp. p. 57).

29 Vid. DPF, h VII, c. XIX, n. 67, p. 62, 1-8 (trad. esp. p. 57).

30 Vid. DPF, h VII, c. XIX, n. 68, p. 62, 9 - p. 63, 21 (trad. esp. p. 58).

31 Vid. DPF, h VII, c. II, p. 97, 9-11 (trad. esp. p. 65).
} 
bajo la persecución (sub persecutione). Dios, dice también, aborrece la tibieza porque es celoso (odit Deus tepiditatem, quia Deus zelotes) ${ }^{32}$.

\section{LeCTURAS RECIENTES}

Imperiosidad de acabar con la violencia religiosa desatada, concordante presuposición de la unicidad, la encarnación y la interna variedad divina en medio de la diversidad ritual, conducción dialogante y razonada a la paz interreligiosa e internacional, tolerancia e incluso valoración de la concurrencia devocional en tanto en cuanto no obste a la unidad de latría: tal es en síntesis el argumento de DPF. Así entendida, esta obra ha tenido una considerable Wirkungsgeschichte, incluso si-como aquí se hará- se consideran solamente las últimas décadas, y esto por el ritmo exponencial al cual ha ido creciendo y por la variedad de perspectivas que ha ido asumiendo desde entonces la interpretación del corpus cusano. Para destacar mejor ese su argumento y ofrecer algunas de las vetas más sensibles o fructíferas del mismo, presento ahora, muy esquemáticamente, una sinopsis de la historia reciente de la interpretación de DPF, justo la que se desarrolla durante el siglo XX, sobre todo a partir de la edición crítica.

2.1. Como se sabe, en 1932 comenzó esta edición crítica de la obra de Nicolás de Cusa: Opera Omnia iussu et auctoritate academiae litterarum heidelbergensis ad codicum fidem edita. Aquel año, en efecto, se publicó el primer volumen de la serie: De docta ignorantia. El texto de De pace fidei, que ocupa el séptimo volumen, fue publicado en 1959 en una edición que estuvo a cargo de Hildebrand Bascour y Raymond Klibansky, y siguiendo a la cual he expuesto los núcleos de la obra ${ }^{33}$. La edición crítica ha coincidido con un notable crecimiento de la literatura secundaria en torno a la famosa obra del Cusano y a su inserción dentro de la marcha intelectual y los avatares políticos y religiosos de la tolerancia en

32 Vid. DPF, h VII, c. II, p. 100, 13-25 (trad. esp. pp. 69-70).

33 Es la edición que he venido citando: De pace fidei cum Epistula ad Ioannem de Segobia, ediderunt commentarisque illustraverunt Raymundus KLibansky et Hildebrandus Bascour, O. S. B. (Hamburg, Felix Meiner, 1959), liii+135 pp. DPF es el título transmitido por los códices $\mathrm{S}, \mathrm{C}$ y $\mathrm{K}$. Otros títulos con los que ha sido conocida esta obra según otros tantos códices son estos (cf. p. LVII y 3): el de T, Dialogus de unitate fidei et sanctarum (sic) diversitate in unum reducenda; el de F, De concordia Religionum; el de D, Incipit dyalogus eiusdem de pace et concordia unice fidei; y el de E, Dialogus... de pace seu concordantia fidei. 
el mundo occidental. De toda esa literatura solo puede darse una breve noticia, la que permitirá después presentar y ocasionalmente discutir más fundadamente algunas cuestiones capitales de DPF.

2.2. Un poco antes de la edición crítica se ubica el conocido punto de vista que desarrolla Cassirer en su libro de $1927^{34}$. Según este, la concentración en el problema del conocimiento hace del Cusano el primer pensador moderno. El primer paso de Nicolás ya tiene sabor moderno, pues consistiría en preguntar no tanto por Dios, sino por la posibilidad de saber acerca de Dios ${ }^{35}$. Por esto es que en DPF se aplica el método de las coiencturae ${ }^{36}$. Ahora bien, agrega Cassirer, la tolerancia cusana no es indiferencia. Y es que la diversidad religiosa está respaldada especulativamente y fundada por la teoría del conocimiento ${ }^{37}$. Los personajes de DPF van exponiendo el significado de la tolerancia para el Cusano. Así, el tártaro dice que la diversidad puede engendrar separación y enemistad, odio y guerra ${ }^{38}$. Pablo, que la fe, no la ley de las obras, salva, lo que vale para el cristiano, el judío y el musulmán. El mismo Pablo, sobre todo, afirma que las costumbres y tradiciones son solo signos sensibles de la verdad de la fe. Vale decir, que la diversidad corresponde a los signos, mas no a lo significado por ellos. En cuanto a lo significado, destaca Cassirer, el Cusano asegura que todas las creencias (incluso las politeístas) participan de la unidad divina y (con mayor o menor cercanía) la presuponen ${ }^{39}$.

34 Ernst Cassirer, Individuum und Kosmos in der Philosophie der Renaissance, ahora en Gesammelte Werke. XIV (Hamburg, Meiner 2002), VII-220.

35 Ernst Cassirer, Individuum und Kosmos in der Philosophie der Renaissance,

36 Ernst Cassirer, Individuum und Kosmos in der Philosophie der Renaissance, 32-34.

37 Ernst Cassirer, Individuum und Kosmos in der Philosophie der Renaissance, 34.

38 Ernst Cassirer, Individuum und Kosmos in der Philosophie der Renaissance, 34.

39 Ernst Cassirer, Individuum und Kosmos in der Philosophie der Renaissance, 3435. Un estudioso de Cassirer, Enno Rudolph, ha dicho que el Cusano desarrolla un "perspectivismo» en tres sentidos: como método del conocimiento de la verdad, o sea, de Dios (en De visione dei), como forma de la verdad (también en De visione dei), y como relativismo cosmovisivo (en DPF), cosa esta última que el autor no desarrolla: vid. "Der häretische Perspektivismus der Rennaisancephilosophie: Cassirers Cusanus», en Ernst Cassirer im Kontext (Tübingen, Mohr Siebeck 2003), 123. 
2.3. Años después, en 1952, Gilson dedica algunas famosas páginas al DPF. Para el Cusano, dice, la religión es un factor de unidad, mientras que las religiones son factores de división ${ }^{40}$. Hay una sola religión -la católica, apostólica y romana-, pero para que a ella puedan adherir las otras religiones del mundo son necesarios ciertos acomodos ${ }^{41}$. Siguiendo a Haubst, Gilson cree que el DPF no es solo el encuentro de la revelación de Cristo con la verdad parcial de las otras religiones, sino también la definición de la paz religiosa como una exigencia del derecho divino y humano, la cual tiene esta consecuencia (dirigida contra las guerras de religión): sola defensio sine periculo est Christiano ${ }^{42}$. Gilson subraya el irenismo del Cusano a lo largo de $\mathrm{DPF}^{43}$. Esta obra no es una exposición integral de la religión católica. Su centro no es la fe cristiana (que de todos modos no está puesta en cuestión por el Cusano), sino la paz religiosa en la tierra a través de una suerte de concordia entre las más diversas creencias ${ }^{44}$. El Cusano, concede Gilson, no sacrifica al cristianismo en el altar de la concordia religiosa mundial, sino que desea con ardor la cristianización total del mundo en vistas de la paz religiosa. Sin embargo, para lograr esta paz recurre a la noción de una sabiduría que acoge la coincidencia de los opuestos, de tal modo que para él parece ser que la intelección de la fe une aquello que la fe divide ${ }^{45}$. Gilson se sorprende de la audacia de un cardenal como es Nicolás, jamás condenada por la iglesia católica, e incluso llega a decir que -en DPF- el Verbo parece haber leído a Nicolás ${ }^{46}$.

40 Étienne Gilson, Les métamorphoses de la cité de Dieu (Publications Universitaires de Louvain-Librairie Philosophique J. Vrin, Louvain-Paris 1952), 155-156.

41 Étienne Gilson, Les métamorphoses de la cité de Dieu, 156, 160-161.

42 Étienne Gilson, Les métamorphoses de la cité de Dieu Gilson, 157 n. 1. Es referencia a la carta a Juan de Segovia (cf. DPF, h VII, c. II, p. 97, 10-11), y en cuanto a Rudolf Haubst, de "Johannes von Segovia im Gespräch mit Nikolaus von Kues und Jean Germain über die göttliche Dreieinigkeit und ihre Verkündigung vor den Mohammedanern», en Münchener Theologische Zeitschrift 2 (1951), 115-129.

43 Étienne Gilson, Les métamorphoses de la cité de Dieu, 155 n. 2 y 180.

44 Étienne Gilson, Les métamorphoses de la cité de Dieu, 180.

45 Étienne Gilson, Les métamorphoses de la cité de Dieu, 180-181.

46 Étienne Gilson, Les métamorphoses de la cité de Dieu, 167. H. U. v. Balthasar, años después, dirá que DPF constituye un aventurado riesgo (ein abenteuerliches Wagnis) que, sorprendentemente, nunca fue incluido en el Index: Das Ganze im Fragment (Einsiedeln, Benziger 1963), 187. H. d. Lubac, luego, agregará que el Cusano es casi un utopista, alguien fascinado por un sueño aparentemente temerario; DPF no 
Poco después, Lecler, en su conocida obra de 1955, dedica unas líneas a DPF. El Cusano es un representante del irenismo humanista, uno cuyo clima religioso es muy diferente del de Bernardo, Tomás o incluso Llull $^{47}$. Nicolás de Cusa está lejos de una rígida ortodoxia. Y lo está, piensa Lecler, debido a sus mismos presupuestos filosófico-teológicos: docta ignorantia, inaccesibilidad de la verdad, alteridad en las aproximaciones y conjeturas humanas, desproporción entre lo finito y lo infinito y sin embargo presencia de esto en aquello ${ }^{48}$. Según el Cusano, añade Lecler, en todo sistema religioso hay una verdad relativa, una participación mayor o menor en la verdad única: cristianismo, judaísmo e islam son aspectos diversos de una misma vía hacia Dios ${ }^{49}$. DPF no es, pues, un tratado teológico, sino una suerte de utopía, un sueño de cristiandad universal a través de la reconciliación de todas las divergencias religiosas. Es un libro audaz ("tan curioso"), en el que el ecumenismo tiende a veces al sincretismo ${ }^{50}$. Y es a la vez un libro que inaugura lo que pretenderán los humanistas: la unidad de las iglesias y sectas -no obstante sus divergencias- sobre la base de algunas grandes verdades comunes, de algunos 'artículos fundamentales'. Lo que propone DPF es, dice Lecler, no un concordato, sino un ideal a perseguir sin pausa ${ }^{51}$.

2.4. Saltando otra vez en el tiempo, y ya sobre la base de la edición crítica de DPF, aparece a mediados de los años ochenta un número especial de las Mitteilungen und Forschungsbeiträge de la Cusanus-Gesellschaft dedicado a la cuestión de la paz en el Cusano. Meinhardt propone allí unos puntos de discusión que han sido muy influyentes. DPF no es una utopía, dice, ni plantea una idea ilustrada de tolerancia como la de

es un programa de acción, sino un texto con carácter más bien apocalíptico: H. D. Lubac, Pic de la Mirandole (Paris, Aubier Montaigne 1974), 299-301. No se crea, sin embargo, que en el campo del catolicismo romano todo es prevención o directa condena. En la actual teología de las religiones, por ejemplo, J. Dupuis incluye al DPF dentro de las obras que mantienen una actitud positiva hacia las religiones no cristianas: J. Dupuis, Toward a Christian Theology of Religious Pluralism (N. York, Maryknoll 2002), 102-109, en especial 107-109.

47 Joseph Lecler, Histoire de la tolérance au siècle de la Réforme. I (Montaigne, Aubier 1955), 127 y 130.

48 Joseph Lecler, Histoire de la tolérance au siècle de la Réforme, 127-128.

49 Joseph Lecler, Histoire de la tolérance au siècle de la Réforme, 128.

50 Joseph Lecler, Histoire de la tolérance au siècle de la Réforme, 128-129.

51 Joseph Lecler, Histoire de la tolérance au siècle de la Réforme, 129. 
Lessing (Nathan y la parábola de los anillos), según la cual la religión es cosa privada e inconmensurable, la verdad (en sentido teórico) resulta relativizada, y solo la praxis decide ${ }^{52}$. Meinhardt concede que la exigencia práctica de tolerancia es indiscutible, pero añade que ella misma necesita una fundada teoría de la verdad. En este sentido, dice, el Cusano no es escéptico ni agnóstico: su docta ignorantia y su afirmación de que el conocimiento humano es coniectura lo hacen defender la idea de verdad y construir una enorme teología especulativa ${ }^{53}$. Por ser conjetural, nuestro conocer nunca capta precisamente la verdad, aunque sí puede acercarse a ella en un infinito proceso de acercamiento. Todo esto vale cuando se trata de conocer a Dios y a las demás cosas (salvo a los objetos matemáticos: solo allí es posible la precisión). Entonces, conocimiento $=$ coniectura $=$ Mutmassung ${ }^{54}$. Si el conocimiento es conjetural, es que la precisión de la verdad es inalcanzable ${ }^{55}$. Pues bien: justo el carácter conjetural, no preciso, del conocimiento humano posibilita e incluso exige la tolerancia religiosa. El saber humano sobre Dios es coniectura: las negaciones teológicas del Pseudo Dionisio son parte de la teología cusana, aunque esta también incluye positivas afirmaciones, pues Dios puede mostrarse y hacerse visible ${ }^{56}$. El Verbo divino hecho carne es la verdad -tal como ella es-, y el hombre se acerca y participa de ella conjeturalmente ${ }^{57}$. Las diversas religiones son coniecturae, aunque sus representantes no suelen darse cuenta de ello. La diversidad (religiosa y no religiosa) es valorada por el Cusano -así se aprecia no solo en DPF sino también en De docta ignorantia ${ }^{58}$. Como conjeturales, las religiones son graduales: ninguna concreta religión podría ser perfectamente idéntica con la verdad tal como ella es ${ }^{59}$. Al comienzo del capítulo III de DPF el Verbo habla de una fides orthodoxa ${ }^{60}$; en cambio, los seres finitos hablan

52 Cf. Helmut Meinhardt, «Konjekturale Erkenntnis und religiöse Toleranz. Der Mutmassungscharakter menschlichen Erkenntnis als Begründung für den Frieden im Glauben», en MFCG 16 (1984), 325-326.

53 Meinhardt, «Erkenntnis», 326.

54 Meinhardt, «Erkenntnis», 326-327.

55 Meinhardt, «Erkenntnis», 327-328.

56 MeinhardT, «Erkenntnis», 328.

57 Meinhardt, «Erkenntnis», 328-329.

58 Meinhardt, «Erkenntnis», 329.

59 Meinhardt, «Erkenntnis», 329-330.

60 Meinhardt, «Erkenntnis», 330. 
de la diversidad (in rituum varietate). Si en Dios hay absoluta unidad, en lo finito solo hay unidad deficiente, por participación, una unidad en la diversidad, pero que es como un contrarreflejo (Widerstrablen) de la absoluta unidad. Tal es el método de DPF: Hinführung, perducere, reducere, conformem facere de la diversidad religiosa a la unidad verdadera y trascendente. Esta unidad refleja (espejea: widerspiegelt) más en unas religiones, menos en otras, pero en ninguna deja de reflejarse, ya que en todas ellas hay un núcleo de verdad. La cristiana es para el $\mathrm{Cu}-$ sano la mayor religión, aunque no por eso la iglesia deja de ser algo que está esencialmente en camino ${ }^{61}$. No solo la tolerancia resulta de estas reflexiones, dice Meinhardt remitiéndose al DPF, sino algo más: concordantia, concordia. O sea, un cordial e íntimo encuentro de las religiones, justo porque comprenden su deficiencia y conjeturalidad de cara a la verdad absoluta: a mayor cercanía unas de otras, mayor cercanía al centro absoluto, y viceversa, en un proceso mundanalmente interminable ${ }^{62}$.

Colomer, también en 1984, hablando de la fuerte deuda que guarda DPF con Llull, dice que el Cusano se halla en una encrucijada de caminos: uno, el de la apologética medieval, y el otro, el del irenismo moderno $^{63}$. Su objetivo no es tanto la conversión de los no cristianos al cristianismo como la coincidencia de todas las confesiones en la única fe cristiana. En tal coincidencia juega un papel esencial la tesis de la praesuppositio. Además, dice, es preciso que los cristianos hagan concesiones para que las demás creencias puedan ser aunadas en la única fe ortodoxa. De ahí que la unidad de fe y religión no implique uniformidad alguna en las formas de expresar la vida religiosa. A lo largo de todas sus obras, el Cusano mantiene el impulso de mediar entre contrarios: en el ámbito político-eclesiástico a través de la concordantia catholica, en el filosófico-teológico mediante la coincidentia oppositorum, y en el de las religiones con la fórmula de la una religio in rituum varietate. $\mathrm{Ni}$ esta ni las anteriores consisten en la igualdad de lo idéntico, sino en la coincidencia de los diferentes ${ }^{64}$.

61 MeinhardT, «Erkenntnis», 331.

62 Meinhardt, «Erkenntnis», 331-332.

63 Eusebi Colomer, "Die vorgeschichte des Motivs vom Frieden im Glauben bei Raimund Llull», en MFCG 16 (1984), 105-106 y 82.

64 Colomer, «Vorgeschichte», 106-107. 
2.5. Poco después Schreiner, en su contribución sobre la tolerancia para Geschichtliche Grundbegriffe, no se pliega a la postura dominante, según la cual la tolerancia de DPF poco o nada tiene que ver con la tolerancia ilustrada, aunque sí sea fundamental en la formación del concepto moderno de tolerancia ${ }^{65}$. El Cusano, dice, pertenece a la tradición de los escépticos - como Sócrates, Erasmo, Montaigne, Locke, Voltaire y Lessing- que han apoyado una irrestricta tolerancia hacia los pensamientos y creencias ajenos, en el entendido de que la limitación del conocimiento humano tiene consecuencias éticas. DPF es temprana manifestación del concepto europeo de tolerantia (aun cuando este sustantivo no aparezca en la obra del Cusano). Nicolás de Cusa no iguala los sistemas de creencias. A partir de su teoría del conocimiento y de su metafísica de la unidad y diversidad, quiere crear las condiciones para la concordia entre las grandes religiones mundiales. Las comunes convicciones fundamentales religiosas, dice Schreiner, son para el Cusano condición de una paz duradera entre los pueblos ${ }^{66}$. La variedad de expresiones religiosas no es concebida por él como fuente de error, sino como chance para el acrecentamiento de la devoción. Las religiones son participationes o explicationes de la única verdad divina: la cristiana con sus dogmas básicos (no con sus ritos, que cambian según la ineluctable ley del cambio histórico ${ }^{67}$. El Cusano, en todo caso, mantiene la pretensión del cristianismo de estar en posesión de la definitiva verdad revelada de Dios ${ }^{68}$. De todas formas, añade Schreiner, este pensador amplió como nunca antes los límites de las divergencias aceptables ${ }^{69}$. Creyó que la concordantia o concordia religionum resulta de un pacífico proceso comunicativo entre las religiones, en cuya virtud puede reconocerse el momento verdadero de cada una por su respecto a la verdad revelada cristiana ${ }^{70}$. Schreiner sigue a Meinhardt cuando dice que el Cusano defiende no solo la tolerantia, sino que va más allá y apuesta por la concordia ${ }^{71}$. Recién los

\footnotetext{
65 Klaus Schreiner, «Toleranz», en O. Brunner, W. Conze y R. Koselleck (eds.), Geschichtliche Grundbegriffe. VI (Stuttgart, Klett-Cotta 1990), 455.

66 SCHreiner, «Toleranz», 459.

SChreiner, «Toleranz», 460.

SChreiner, «Toleranz», 461.

69 Schreiner, «Toleranz», 460.

70 SChreiner, «Toleranz», 461.

71 Schreiner, «Toleranz», 460-461.
} 
ilustrados determinarán en detalle la tolerancia moderna, pero usando los presupuestos de la concordia cusana: la diversidad no es enemiga de la unidad, sino expresión de la única e inalcanzable verdad ${ }^{72}$.

2.6. McTighe, por la misma época, se revela como un lector original de DPF. En su opinión, ningún intérprete aporta pruebas textuales en DPF para ligar la fórmula una religio in rituum varietate con las categorías de la metafísica cusana de la unidad: complicatio-explicatio, exemplar-imago, ante omnem pluralitatem est unitas ${ }^{73}$. El in de dicha fórmula puede ser entendido con la palabra neutral, no técnica, praesupponitur. Por ello una religio in rituum varietate permanece notablemente libre de interpretación metafísica ${ }^{74}$. Tampoco es usado en DPF el lenguaje chartriano de unitas-alteritas para ligar religio y ritus. Claro: religio y ritus deben distinguirse, pues religio $=$ cultus unius dei, mientras que ritus $=$ combinación de ideas y prácticas ${ }^{75}$. La pregunta grave es si el cristianismo es la una religio absoluta y verdadera, la Ur-Religion, la complicatio-religión, o si es más bien un rito, una explicatio de la una religio. Si el cristianismo es una cosa finita, como parece ser, entonces es parte de la explicatio: una forma finita de religio entre otras. Además, si es así, para él vale lo que vale para toda explicatio según la docta ignorantia: que es dominio del

72 Schreiner, «Toleranz », 461. Wieland, por ej., no está totalmente de acuerdo. Se pregunta: ¡es la una religio magnitud histórica o idea escatológica?: G. Wieland, «Das Eigene und das Andere: theoretische Elemente zum Begriff der Toleranz im hohem und späten Mittelalter», en A. Patschovsky y H. Zimmermann (eds.), Toleranz im Mittelalter (Sigmaringen, Thorbecke 1998), 22. A favor de la interpretación escatológica está la idea del conocimiento humano como coniectura: la verdadera religión como idea escatológica a la que nos aproximamos en un proceso interminable. Pero, dice Wieland, las religiones históricas son ellas mismas conjeturales, son aproximaciones a -o participaciones en- la única y verdadera religión. Entonces, debiera admitirse que los diversos ritos están en camino hacia el objetivo único de la verdadera religión. Y por eso -en perspectiva cusana- la diversidad no es mera carencia ni negatividad, sino expresión del conocimiento humano conjetural, incluso chance para una mayor devoción (como se sugiere en DPF). Según esta interpretación, el Cusano se aproxima a la idea de Lessing de tolerancia, aunque sin coincidir por entero con ella: Wieland, "Toleranz», 23.

73 Thomas McTighe, «Nicholas of Cusa's Unity-Metaphysics and the formula religio una in rituum varietate», en G. Christianson y T. IzBicki (eds.), Nicholas of Cusa in search of God and Wisdom (Brill, Leiden et alii 1991),162-166.

74 McTighe, «Metaphysics», 168.

75 McTighe, «Metaphysics», 169. 
plus aut minus. De hecho, hay intérpretes que creen que el cristianismo es lo más cercano a la religio absoluta. En verdad, si es la una religio y a la vez es una forma finita de religión, entonces el cristianismo no debe ser sometido a las ya mencionadas categorías metafísicas del Cusano ${ }^{76}$. Estas categorías pueden servir ad intra (los ritos orientales y occidentales son explicationes del cristianismo), pero no sirven ad extra (en la relación del cristianismo con las demás religiones), y por ello conviene-como el Cusano- emplear fórmulas vagas como concordia, pax, una fides orthodoxa ${ }^{77}$. Tal vez la ambigüedad de la fórmula una religio in rituum varietate se debe justamente no a la presencia, sino a la ausencia de las categorías metafísicas usuales en el Cusano ${ }^{78}$.

2.7. En su conocida Habilitationsschrift sobre la tolerancia, publicada el 2003, Forst propone un marco general para llevar a cabo luego cualquier discusión histórica o sistemática. Enumera tres componentes de la tolerancia (cada uno, claro, acompañado de alguna razón): rechazo (Ablehnung), aceptación (Akzeptanz), recusación (Zurückweisung) ${ }^{79}$. Y habla de cuatro concepciones de la tolerancia. $1^{\text {a }}$ la Erlaubnis-Konzeption: la de la permissio mali, que es típicamente vertical (por ej., el Edicto de Nantes de 1598$)^{80} .2^{\text {a }}$ la Koexistenz-Konzeption: la del permiso pragmático-instrumental para preservar la coexistencia pacífica, típicamente horizontal (por ej., parcialmente, el Leviathan de Hobbes) ${ }^{81}$. 3a la Respekt-Konzeption: la del permiso moral que supone reciprocidad, según la cual tolerante y tolerado son personas autónomas, ciudadanos de la comunidad política que se reconocen, y que toleran, no sus personas (eso es algo a respetar), sino sus convicciones y acciones. Dos variedades hay aquí: la de la igualdad formal, que supone estricta separación entre una esfera privada y una pública, y la de la igualdad cualitativa, en la que no hay tan estricta separación, pues se piensa que la igualdad formal es potencialmente intolerante (por ej. cuando se prohíbe en su nombre el uso de

\footnotetext{
McTighe, «Metaphysics», 170.

McTighe, «Metaphysics», 171.

78 McTighe, «Metaphysics», 172.

79 Rainer Forst, Toleranz im Konflikt. Geschichte, Gehalt und Gegenwart eines umstrittenen Begriffs (Frankfurt a. M., Suhrkamp 2003), 30-41 y 530-533.

80 Forst, «Toleranz», 42-44.

81 Forst, «Toleranz», 44-45.
} 
atuendos religiosos en la escuela pública ${ }^{82}$. Y $4^{a}$ la Wertschätzung-Konzeption: la de la tolerancia afirmativa (hay que preguntarse, claro, por el papel del componente de rechazo en esta concepción), la tolerancia del pluralismo valorativo, la que, más que permiso, es valoración de otras prácticas y convicciones, y que es característica de algunas tendencias multiculturalistas $^{83}$. Aún menciona Forst los posibles caminos hacia la unidad, pensados y realizados para la superación (Überwindung) de la pluralidad religiosa: la unidad reductiva, la unidad a través de la fusión, la unidad competitiva, la unidad inclusiva, la unidad pluralista y la unidad a través de la refutación ${ }^{84}$.

Con este utillaje teórico, Forst dice que la tolerancia de ritos es defendida por el Cusano sobre la base de razones pragmáticas: la tolerancia es medio para producir la paz religiosa mediante la unidad religiosa ${ }^{85}$. Pero ninguna verdad contienen las demás religiones que no estuviera ya en el cristianismo: ellas solo poseen alguna (unilateral) porción de la verdad. En DPF no hay, como en Abelardo y Llull, un enfrentamiento con los contenidos creyentes de las otras religiones. De hecho, los representantes de estas asienten muy rápidamente a la verdad cristiana ${ }^{86}$. El sueño de una paz en la fe es así el sueño de una paz católica que deja espacio para las diferencias rituales (= adiaphora). La argumentación (1) parece seguir el camino humanista de la unidad reductiva: unidad a través de la vuelta al núcleo religioso común a todo hombre (sin perjuicio de las diferencias rituales). Pero también (2) sigue el camino de la unidad inclusiva en la medida en que la religión cristiano-católica envuelve la verdad de todas las demás religiones y es, por ello, la religión perfecta que puede tolerar los ritos de las otras. A veces también (3) parece seguir el camino de la unidad mediante la refutación de las demás religiones en tanto que ellas son más bien formas más o menos erradas (y verdaderas) de religión. Así, se ve cuán lejos está el Cusano (y en general la edad media) de una comprensión pluralista de la religión como la de Lessing y otros. $\mathrm{El} \mathrm{Cu-}$ sano, en DPF, defiende una postura más tradicional que la de Abelardo: no pretende como este la unidad que posibilita la paz religiosa a través

\footnotetext{
Forst, «Toleranz», 45-47.

Forst, «Toleranz», 47-48.

84 Forst, «Toleranz», 104 y, críticamente, pp. 536-539.

85 Forst, «Toleranz», 107.

86 Forst, «Toleranz», 108.
} 
de una doctrina ética racional (= ley natural), sino a través de la entera fe cristiana $^{87}$. La radicalidad de la teología negativa del Dios inefable y de la teoría conjetural del conocimiento (= docta ignorantia, coniectura) no se aplica a la religión. Si se aplicara, las religiones serían entendidas como conjeturas de espíritus finitos, la religio una sería algo compartido pluralmente por los habitantes del mundo, y Dios permanecería incomprehensible ${ }^{88}$. La finitud de la razón lo hubiera llevado a una teoría pluralista de la religión, piensa Forst, pero de hecho ella no es el fundamento de la idea cusana de tolerancia. La verdadera religión no tolera la arrogante pretensión del conocimiento humano, como tampoco la relativización de su contenido a través de una intelección situada en los límites de la razón humana ${ }^{89}$. Todo esto conduce a Forst a la conclusión de que en el Cusano hay un impulso irenista, pero uno bien escaso ${ }^{90}$.

2.8. En el ámbito hispanohablante es Álvarez-Gómez el responsable de la mejor y más persistente interpretación del Cusano en general y del DPF en particular. En un texto de 2003, sobre la paz según Juan de Segovia y Nicolás de Cusa, hace un útil paralelo. Ambos, dice, coinciden en querer evitar la guerra. Aunque la guerra defensiva sea justa, buscan la paz, y una paz perpetua ${ }^{91}$. Coinciden también en que el diálogo con los otros creyentes (no cristianos) ha de apelar a la razón o inteligencia ${ }^{92}$, en haber tenido experiencias personales que hacen valorar toda posibilidad de evitar la guerra, y en pensar que, necesaria y todo la paz, deben quedar a salvo las afirmaciones fundamentales de la fe y la lealtad a la Iglesia Católica, así como la aceptación de sus decisiones ${ }^{93}$. Divergen, primero, por la amplitud del cuestionamiento: para Juan, es la relación entre cristianismo e islam, para Nicolás, es la relación -y una que se plantea a través de un diálogo filosófico- entre todas las religiones (por eso la

\footnotetext{
FORST, «Toleranz», 109.

Forst, «Toleranz», 109-110.

Forst, «Toleranz», 110.

Forst, «Toleranz», 130.

91 Mariano Álvarez Gómez, Über die Bedingungen des Friedens im Glauben bei Johannes von Segovia und Nikolaus von Kues (Trier, Trierer Cusanus Lecture Paulinus 2003), 12.

92 Álvarez Gómez, Bedingungen, 12-15.

93 Álvarez Gómez, Bedingungen, 15-16.
} 
distinción entre las diversas religiones concretas y religio ${ }^{94}$. Segundo, el objetivo común, la paz, es diversamente acentuado: para el de Segovia el objetivo es la conversión musulmana, siendo la paz el medio para ello, mientras que para el Cusano la paz no es medio para la conversión, sino el objetivo mismo (es lo que expresa la fórmula una religio in rituum varietate $)^{95}$. Tercero, por lo que toca a las preguntas sobre las que la disputa teológica debe concentrarse, Juan es muy optimista, y el Cusano no $\operatorname{tanto}^{96}$. Y cuarto, respecto del método o reglas para una adecuada confrontación, Nicolás evita atacar a los no cristianos, en especial al islam, en tanto que Juan es más agresivo y descalificador con él ${ }^{97}$.

94 Vid. DPF, h VII, c. I, n. 1, p. 4, 1-5. Cf. Álvarez Gómez, Bedingungen, 17-20.

95 Álvarez Gómez, Bedingungen, 20-22.

96 Álvarez Gómez, Bedingungen, 22-23.

97 Álvarez Gómez, Bedingungen, 23-25. Antes, en 2002, Álvarez Gómez había escrito un artículo sobre consenso y verdad en el Cusano, que avant la lettre viene a prolongar el anterior. Dios actúa al modo humano: «[...] la innegable aceptación de la trascendencia corre pareja con la no menor acentuación de la inmanencia»: Mariano Állvarez Gómez, "Consenso y verdad en la religión según Nicolás de Cusa", en M. Álvarez Gómez (ed.), Pluralidad y sentido de las religiones (Salamanca, Ediciones de la Universidad de Salamanca 2002), 52. Si bien el Cusano suplica a Dios moderar la crueldad de la persecución en Constantinopla, la dirección de su discurso se abre más allá de ese hecho, proyectándose explícitamente en perspectiva universal. El Cusano quiere que las guerras religiosas terminen definitivamente. Esta aspiración gana con el Cusano una nueva radicalidad, primero en la idea, solo posteriormente en la realidad. Pero el asunto tiene sus bases conceptuales, dice Álvarez Gómez. El símil de la caverna (Deus absconditus para el hombre, el hombre como espíritu intelectual 'envuelto en sombras' para sí mismo) recorre toda la obra del Cusano, incluyendo DPF. Nicolás de Cusa, según Álvarez Gómez, une las tradiciones griega y bíblica: Dios creador, unión humana con Él en tanto que caridad suprema, retorno humano al origen (Álvarez Gómez se refiere a STh I, 1, a. 7, introd. y a ScG, proemio al libro III). Acoge los derechos de la razón, tanto en la forma del credo ut intelligam como en la del fides quaerens intellectum, pero enfatizando que la razón abre los ojos a la fe respecto de los presupuestos de esta, desde los cuales emerge la posibilidad de la concordia religiosa. Las religiones, sigue Álvarez Gómez, han de abordarse teológicamente según el Cusano, vale decir, desde la perspectiva de la verdad. Sin embargo, de acuerdo al DPF, hay que distinguir esencialmente entre la palabra de Dios mismo -el infinito y la de los profetas- seres finitos. Así como, en general, hay que distinguir entre las costumbres religiosas y la verdad, entre lo relativo y lo absoluto. El Cusano, enfatiza Álvarez Gómez, no es relativista. La tolerancia solo se justifica desde la verdad, y la concordia buscada se funda también en la verdad. Dios es la verdad, el bien, la vida, el ser: no hay diferencia entre el Dios de la metafísica y el de las religiones. La diferencia entre 
2.9. Por su detallada dedicación al DPF, Riedenauer es otro autor importante. Piensa, como Lewis y Niewöhner, que no hubo casi diálogo interreligioso en la edad media ${ }^{98}$. Hay distintos niveles discursivos, difíciles de diferenciar, en la reacción medieval a las religiones extrañas a la propia: la violenta y militarizada, la misionera, la teórica por argumentación racional. Una real confrontación interreligiosa requiere una buena comprensión del extraño y criterios y métodos no particulares sino universalizables, vale decir, filosóficos ${ }^{99}$.

Pues bien: en su habilitación del año 2007 Riedenauer aborda extensamente la pluralidad religiosa a partir del pensamiento de Nicolás de Cusa. La suya es una lectura sistemática de DPF, una que reúne sus motivos prácticos, teológicos, culturales, metafísicos, epistemológicos, antropológicos y éticos. Esta multitud de motivos hace que la misma fórmula religio una in rituum varietate sea difícil de entender. Hay interpretaciones que van desde la identificación de esta fórmula con la docta ignorantia, pasando por la aceptación de una -lo que también valdría para el cristianismo- presupuesta o dominante religión originaria (Urreligion), hasta la identificación de ella con el cristianismo católico. Casi nadie ha estudiado los elementos dialógicos y teorético-discursivos de DPF ni propuesto una idea histórica e inculturada de religión ${ }^{100}$. Tal es

Dios y las diversas costumbres religiosas no debe ser anulada. Tal diferencia impide absolutizar lo relativo y permite seguir buscando -en interminable aproximaciónla verdad divina. El del Cusano es el camino socrático de la liberación por el conocimiento, sí, pero que sabe que en definitiva la paz de la fe no se logra por mero consenso racional si previamente Dios mismo no revela su verdad. Las diferencias religiosas se legitiman desde su 'incardinación' en la raíz única y fundamental. Dicha verdad religiosa está sobre todo en el cristianismo, y en las demás religiones en tanto en cuanto el cristianismo está más o menos presupuesto en ellas (cf. Álvarez Gómez, «Consenso», 52-72).

98 Markus Riedenauer, "Das Mittelalterliche Christentum in Auseinandersetzung mit dem Islam», en Ch. Schäfer y M. Thurner (eds.), Mittelalterliches Denken. Debatten, Ideen und Gestalten im Kontext (Darmstadt, WBG 2007),105-106. Es referencia a Bernard Lewis y Friedrich Niewöhner, "Vorwort», en B. LeWis y F. NiewöHner (eds.), Religionsgespräche im Mittelalter (Wiesbaden, Harrassowitz 1992), 7-9.

99 Riedenauer, «Islam»,106.

100 M. Riedenauer, Pluralität und Rationalität. Die Herausforderung der Vernunft durch religiöse und kulturelle Vielfalt nach Nikolaus Cusanus (Stuttgart, Kohlhammer 2007), 105, 121 y 126. 
la intención de Riedenauer. Su reconstrucción del pensamiento cusano en torno a la paz en la fe se organiza en torno a variados niveles reflexivos: los de la antropología, teoría del conocimiento, metafísica, teoría de la religión, ética y política ${ }^{101}$. Con este background, Riedenauer expone la teoría cusana de la religión y de la racionalidad del conocimiento religioso. Según esta, la razón humana está desafiada. Su búsqueda del Dios escondido trasciende la lógica: la coincidencia de los opuestos ocurre efectivamente en lo infinito, si bien Dios mismo transciende incluso aquella coincidentia. Los conceptos positivos de Dios son limitados. Dios no solo escapa a las contradicciones y a las categorías humanas, sino que se adelanta al hombre: omnis quaestio de deo praesupponit quaesitum $^{102}$. Según Riedenauer, De coniecturis va más allá de De docta ignorantia cuando dice que hay cuatro regiones del ser: Dios, intelecto, alma (= ratio), cuerpos (= sensus), y cuatro modos de la verdad: veritas, verum, verisimile, confusio ${ }^{103}$. En cuanto al discurso interreligioso,

101 Riedenauer, Cusanus, pp. 105-106. La antropología del Cusano tiene cierta prioridad sobre la cristología: primo es homo; secundo Christianus Sermo CXVIII, h XVII, n. 10, 13 (cf. M. Riedenauer, Cusanus, p. 223 n. 3). La imagen del hombre del Cusano no es medieval ni moderna (cf. M. Riedenauer, Cusanus, p. 288). En su opinión, el espíritu o mens que conoce es el sujeto de la religión (cf. M. Riedenauer, Cusanus, p. 223). Particular es la posición del hombre en el mundo como imagen viviente de Dios, como ser artístico que se configura libremente, como espejo móvil de la belleza (cf. M. Riedenauer, Cusanus, pp. 239-250 y 320 329). De aquí surge una ética. La del Cusano es una ética de la virtud, una teoría de la ley natural (en la que la regla de oro, el amor a Dios y al prójimo, juega un papel esencial), una ética racionalmente fundada y conectada con la religión (por el impulso o aspiración connata del hombre a la felicidad y a la vida eterna, das Streben). La metafísica del conocimiento del Cusano, enseguida, está estrechamente vinculada con la tradición de la teología negativa. Conforme a De docta ignorantia y De coniecturis, el humano conocimiento es comparativo-discursivo, gradual, conjetural, tiene un horizonte y se desarrolla en alguna perspectiva. Para el Cusano, la perspectividad es una estructura fundamental del mundo. Por ello puede decir: homo non potest iudicare nisi humaniter: (vid. De visione dei, h VI, c. VI, n. 19, p. 21, 15-16). La visión de Dios es tanto la humana que recae sobre Dios como la divina que recae sobre la humana (de visione dei es, pues, genitivus subiectivus y obiectivus). No hay más constitución humana que a través de lo infinito (cf. M. Riedenauer, Cusanus, pp. 250-279 y 298-320).

102 Cf. Idiota. De sapientia, h V, 1. II, c. I, n. 29, p. 60, 18. Riedenauer, Cusanus, pp. 334-350.

103 Cf. De coniecturis, h III, p. I, c. IV, n. 15, p. 20, y p. II, c. XVI, n. 157, pp. 156-157. 
el Cusano afirma que no es antirracional ni irracional. Es un ámbito en el que la racionalidad está fuertemente limitada y en el que domina, no el escepticismo, sino una docta o sacra ignorantia ${ }^{104}$. DPF es un diálogo sobre, con y en Dios. Y De visione dei, escrito inmediatamente después de DPF, permite decir que la búsqueda de Dios es individual y a la vez intersubjetiva ${ }^{105}$. La religiosidad se despliega. Es religio una in rituum varietate. He aquí los condicionamientos naturales y culturales de la religión ${ }^{106}$.

¿Cuáles son las consecuencias éticas y políticas de DPF? Nicolás enfatiza la libertad en $\mathrm{DPF}^{107}$. Los hombres, dice Riedenauer, buscan en las diversas religiones un único ser, cuya verdad permanece oculta e inexpresable para todos ellos, ¡incluso para los católicos! ${ }^{108}$. En el concepto de racionalidad del Cusano se aprecia la razón cosmológico-objetiva antigua y -conectada con la fe en la creación-medieval. Pero a la vez, ella es transformada, pues el Cusano pone en paralelo a la creatividad divina con la humana. Entonces, la ontología se vuelve una ontodialógica: el mundo, como signo de Dios, oferta de comunicación, posibilita una religiosidad universal, y cada hombre vive, por su facultad cognoscitiva, en esta disposición ontodialógica ${ }^{109}$. Según Riedenauer, y contra lo que piensa el propio Forst, elementos de las cuatro concepciones de la tolerancia que este autor enumera aparecen en el Cusano ${ }^{110}$. La verdad no obsta, como cree Forst, a la tolerancia: su misma sublimidad puede fundar perfectamente el mandato de la tolerancia. Todas estas tesis del Cusano tienen fortalezas y debilidades ${ }^{111}$. Sea de ellas lo que fuere, hay

104 M. Riedenauer, Cusanus, pp. 351-358.

105 M. Riedenauer, Cusanus, pp. 369-374. Vid. prólogo de De visione dei.

106 M. Riedenauer, Cusanus, pp. 412-421.

107 Cf. DPF, h VII, c. II-III, n. 7-9, pp. 8-10.

108 Cf. DPF, h VII, c. I, n. 5, p. 6, 14ss. M. Riedenauer, Cusanus, p. 438 n. 2.

109 M. Riedenauer, Cusanus, pp. 441-442.

110 M. Riedenauer, Cusanus, pp. 452-455.

111 No cabe duda, dice Riedenauer, de las claras deficiencias del modelo cusano en DPF respecto de las religiones asiáticas. De todos modos, la fuerza impulsiva existencial de búsqueda y pensamiento es la fascinación por la infinitud (cf. M. Riedenauer, Cusanus, pp. 448-449). Su intención fundamental es salvar la infinitud de Dios y la capacidad divina de cada hombre contra la tendencia de las religiones -también la cristiana- de reducirlas a objetos comprobables (vid. De beryllo, h XI/1, n. 32, 8-13). El Cusano insiste una y otra vez en el eterno 
en DPF una teoría de la religión cristiana e integradora. La cristología de la obra es filosófica. Cristo, como unificación del maximum absolutum (Dios) y del maximum contractum (universo), expresa la idea cusana de la coincidencia ${ }^{112}$. Es excepcionalmente importante, desde el punto de vista eclesiológico, lo que dice Nicolás en carta a Rodrigo Sánchez de Arévalo de 1442, allí donde distingue entre ecclesia coniecturalis y ecclesia occultata o ecclesia ipsa ${ }^{113}$. Es justo por ello, dice Riedenauer, que la teoría religiosa del Cusano es inclusivista, lo que implica una suerte de relativización religiosa abierta al diálogo ${ }^{114}$. Esto obliga a evitar, dice, tanto el relativismo - no el perspectivismo- como el esencialismo - no la verdad. Es lo que hace el Cusano empleando una antropología en la que la creatividad humana está en el centro y lo que el hombre piensa y hace es interpretado como explicatio. Desarrollando una teoría del conocimiento en la que la perspectividad y discursividad son reconocidas, admite que hay progreso temporal y movilidad del conocer. Expone la racionalidad en su interna diferenciación: sensus-ratio-intellectus. Y muestra la momentánea limitación de toda explicación como algo a trascender en pos de la verdad cada vez y de manera dialógica. Así, la confrontación histórica de una religión con otras le exige cierta madurez. La identidad de una religión, análogamente a la de una persona, es dinámica y más o menos cambiante. Si la religión implica una interpretación integral de la realidad desde una determinada perspectiva, entonces inevitablemente tendrá - por su propio objeto- carácter conjetural. Tal interpretación no es arbitraria ni tampoco definitiva. Su fuerza integradora, que debe responder airosamente a los desafíos históricos, es respecto de los individuos criterio de su propia madurez. De ahí la necesidad de la crítica y la autocrítica.

\footnotetext{
impulso, la interminable aproximación humana a Dios. Por lo mismo, ejecuta una autorrelativización del pensamiento cristiano en beneficio de la infinitud divina. El Cusano quizá es consciente de que el proyecto de DPF es demasiado exigente para con la mayoría de los creyentes religiosos (por eso la presencia de los sabios, en vez de representantes religiosos, en la obra). Además, el ateísmo casi no aparece, falta trabajar hermenéuticamente la tendencia mística infinita en las distintas religiones, se descuida el discurso práctico e incluso jurídico que debiera acompañar a la metafísica, a la teoría del conocimiento y a la filosofía de la religión del DPF.

112 M. Riedenauer, Cusanus, pp. 455-463.

113 Cf. h XV/2, pp. 3-16. M. Riedenauer, Cusanus, p. 469 n. 80.

114 M. Riedenauer, Cusanus, pp. 475-482.
} 
Para Riedenauer, Nicolás de Cusa sabe que la confrontación con otras religiones exige disponer de una autocomprensión integradora. Es justo lo que pretende hacer con el cristianismo, aunque sin parar mientes en que este también puede ser objeto de la autocomprensión integradora de las demás religiones. Por ello su inclusivismo epistemológico no llega a ser recíproco o mutuo (mutuell). DPF tiene la debilidad de no dialogar directamente con el núcleo de las otras religiones. Y es que una religión en confrontación con otras puede ampliar su horizonte en dirección hacia lo inefable. El proyecto cusano, en cualquier caso, tiene la virtud filosófica de rediseñar los límites de las propias explicationes religiosas, de lograr una cierta autorrelativización. En general, dice Riedenauer, DPF indica la posibilidad y la necesidad de que, en el discurrir interreligioso, las religiones, ampliando sus fronteras e ilustrándose filosófica y teológicamente, encuentren novedosos puntos de contacto y coincidencia. El problema, claro, es que ese encuentro puede situarse fuera del núcleo de cada religión, estropeando el objetivo ético-pacífico que impulsa el diálogo. El Cusano apunta todavía a otro modelo de diálogo, uno en el que se produzca la ampliación de los horizontes de cada religión y en el que la coincidencia entre las religiones no sea solamente periférica, sino también central y nuclear. En tal caso, el objetivo será la aproximación incesante, interminable al horizonte divino, que es maximum por definición ${ }^{115}$. Este modelo sí que constituye un inclusivismo mutuo o recíproco, pero uno que en estricto rigor va más allá de las explícitas intenciones del Cusano. El modelo anterior, el de la estratificación o superioridad jerárquica o inclusividad unilateral, tiene un problema (Riedenauer sigue a McTighe): supone que podemos saber que el cristianismo está más cerca de la verdad absoluta que las demás religiones. Empero, según la teoría conjetural del conocimiento, nadie conoce la unidad o complicatio. Por eso la pluralidad es insuperable, y el pensar y actuar tolerante está bien fundado cognoscitivamente ${ }^{116}$. La epistemología del Cusano -con su diferenciación entre ratio e intellectus- expresa una racionalidad finita. Para la religión es útil la razón filosófica, y viceversa ${ }^{117}$. El diálogo pacífico es la forma cultivada de enfrentar la contradicción de pretensiones universales de verdad de las religiones (que a veces se encara

\footnotetext{
115 M. Riedenauer, Cusanus, pp. 493-496.

116 M. Riedenauer, Cusanus, p. 497.

117 M. Riedenauer, Cusanus, pp. 498, 500 y 502.
} 
bronca, violentamente incluso). La paz no es solo el objetivo del diálogo, sino también la condición de posibilidad para la búsqueda dialógica de la verdad. La razón finita y perspectivista necesita del diálogo. Según Riedenauer, esto es lo que hace que ella supere el inclusivismo unilateral y pueda (y deba) marchar hacia uno recíproco ${ }^{118}$.

2.10. Son muy numerosas, en verdad, las interpretaciones dadas en estas últimas décadas a $\mathrm{DPF}^{119}$. Aunque todas, en su misma acumulación, permiten hacerse una idea más rica de la obra, no todas ellas son especialmente fructíferas. Entre las que sí lo son destácanse especialmente las de Gilson, Lecler, Colomer, Forst, Álvarez Gómez, Meinhardt, McTighe y Riedenauer. Gilson subraya muy católicamente la cuasi heterodoxia que exhibe Nicolás en DPF. Lecler y Colomer, en cambio, destacan el católico irenismo del Cusano. Forst muestra que DPF debe ser abordado conceptual y sistemáticamente, en particular desde alguna teoría general de la tolerancia, de sus componentes, concepciones y límites. Álvarez Gómez, al modo de tantos estudiosos alemanes, tiende a releer DPF a la luz del entero sistema cusánico e, incluso, sobre el telón de fondo de otras filosofías anteriores y posteriores: platónicas, neoplatónicas, racionalistas, idealistas. Meinhardt propone, con toda razón, que la conjeturalidad fuertemente acentuada por Nicolás de Cusa es y debe ser clave de lectura del DPF -y esto, agregaría uno, incluso contra expresiones del propio autor que pudieran poner en duda la conjeturalidad también envuelta en la creencia cristiana. McTighe, por lo mismo, rechaza aplicar al DPF nociones metafísicas que el propio Cusano no ha empleado en dicha obra, lo que permite exhibir limpiamente la tensión inscrita entre la afirmación de la verdad cristiana y el carácter conjetural del cristianismo en lo que tiene de juicio humano. Riedenauer, por último, enfrenta DPF de manera imparcial, sin ocultar sus debilidades, pero tratando de explotar detalladamente sus posibilidades teóricas y prácticas -en especial por su filosofía de la libertad- de cara a las actuales exigencias éticas, antropológicas y epistemológicas del diálogo interreligioso.

118 M. Riedenauer, Cusanus, pp. 501-502.

119 En otro lugar he destacado la de Euler y, sobre todo, la de Nederman, quien pone de relieve que DPF gana en inteligibilidad cuando se lo inserta dentro de una investigación fuertemente histórica de la tolerancia en la edad media y en la época moderna (cf. E. Solari, "Contornos de la tolerancia medieval» [inédito]). 


\section{Algunas cuestiones}

Si se lee atentamente DPF, y se lo hace a la luz de la historia de su misma efectividad, surgen preguntas respecto del texto mismo, de su más profundo sentido y de aquello que en un texto lejano aún pueda ser pertinente en nuestros días. En efecto, los problemas históricos y sistemáticos que de allí brotan y merecen pensarse son considerables. Conviene, en esta última sección, plantearlos sucintamente y discutir algunos de ellos.

3.1. Una primera cuestión es la del uso que hace el Cusano de términos como fides, religio, cultus, secta, ceremonia, unitas, diversitas, concordia, pax, tolerare y otros por el estilo, asunto al que se han dedicado estudios independientes y detallados ${ }^{120}$. Particularmente, qué sea tolerar para el Cusano requiere identificar, en medio de diversas y concurrentes concepciones de la actitud tolerante, sus componentes mínimos. Para ello es preciso disponer de una idea clara de lo que tolerantia suele y puede significar ${ }^{121}$. Por otro lado, es necesario atener a los estudios que ubican esta obra en su propio marco histórico: la Europa cristiana del convulso siglo XV, y, más allá, procesos amplios como los de los avatares medievales de la tolerantia, la crisis de la respublica christiana, el alumbramiento de los nacionalismos, las guerras inter e intrarreligiosas y, como veremos, la emergencia del renacimiento.

3.2. En particular, ha de reconocerse que la antigua tesis de Cassirer -que ve en DPF un preanuncio de la tolerancia moderna y en el pensamiento del Cusano una ilustración avant la lettre- no ha desaparecido del todo. Favorable a la idea de Cassirer es Schreiner, como se vio. Pero también lo es Blumenberg, quien, en La legitimidad de la época moderna, y aun sin mencionar DPF, hace ver la conveniencia de colocar a la filosofía cusana dentro de una visión más amplia de la historia occidental y en el umbral de dos de sus épocas, la medieval y la moderna, marcada

120 Solo por ej., vid. el acápite reservado al Cusano en la vasta indagación que ha hecho E. Feil en torno a la noción de religio: E. FeIL, Religio. I: Die Geschichte eines neuzeitlichen Grundbegriffs vom Frühchristentum bis zur Reformation (Göttingen, Vandenhoeck \& Ruprecht 1986), 138-159.

121 Como la que dice que es esa actitud proposicional que acepta creencias y valoraciones ajenas, pero que tiende a hacerlo distanciada, críticamente, justo por no coincidir con ellas ni en principio aprobarlas: cf. A. VIGO, «El concepto de tolerancia», en Revista de Humanidades - Filosofía. Universidad Nacional Andrés Bello 4 (1999), 125-149. 
aquella por el absolutismo teológico y esta no por la mera secularización de lo teológico, sino por el advenimiento de un nuevo mundo, el de la autoafirmación humana ${ }^{122}$.

Al mismo tiempo, debe subrayarse que, a la luz de la masa interpretativa que hemos examinado, parece imprescindible dar un paso previo $y$, antes de embarcarse en semejante 'modernización' de Nicolás de Cusa (la que pone en una misma línea a DPF con el decurso moderno de la tolerancia), asumir el trabajo de ubicar detalladamente la idea cusana de concordia interreligiosa en plena Edad Media ${ }^{123}$. Y es que la tolerancia no solo ha tenido el contenido histórico que le han dado los modernos, sino también el que le dieron los medievales ${ }^{124}$. En todo caso, también debe preguntarse -lo más precisamente que sea posible, sin retóricas ni los descontrolados prejuicios apologéticos o condenatorios que exhiben algunos intérpretes, como hemos visto- por el relieve de DPF para la posterior concepción moderna de la tolerancia religiosa y política de autores como Spinoza, Bayle y Locke, así como para las actuales discusiones culturales y jurídicas en torno a la misma y respecto del pluralismo, las derivas fundamentalistas, etc.

3.3. Se trata, además, como suele hacer la literatura mencionada, de delinear las tesis de DPF al interior de la entera filosofía de Nicolás. En cuanto a esto, y sin pretender que toda la filosofía del Cusano tenga que estar recogida en DPF, es ostensible que hay numerosos loci en el corpus cusánico que de distintas formas afirman e incluso hacen apología de la unidad, coincidencia o concordancia, en el entendido de que esta no destruye sino que puede admitir e incluso favorecer la diversidad, siendo entonces posible y deseable pretender alguna unidad en la diversidad ${ }^{125}$.

122 Hans Blumenberg, Die Legitimität der Neuzeit (Frankfurt a. M., Suhrkamp 1996), 558-638..

123 Junto al ya mencionado Nederman, Bejczy es otro autor que ha prestado una útil contribución en situar medievalmente a la tolerancia: cf. István Bejczy, "Tolerantia: a Medieval Concept», en Journal of the History of Ideas 58/3 (1997), 365-384.

124 Cf. nuevamente E. SolarI, «Contornos de la tolerancia medieval» [inédito]..

125 El ya mencionado M. Álvarez Gómez ha planteado una sugerente discusión ontológica sobre el pluralismo. La tradición, desde Platón hasta Nietzsche, pasando por Aristóteles, Tomás de Aquino, Leibniz y Hegel, ha concebido la pluralidad sustentada en la unidad y a esta como explicitándose en aquella. El contemporáneo pluralismo -que no es solo el hecho de la pluralidad de doctrinas, sino el pluralismo 
Hemos visto que en DPF la unidad presupuesta, no otra que la de una interpretación esencial del cristianismo, deja afuera a ritos como la circuncisión y a sacramentos como la eucaristía, poniendo al menos en entredicho la estricta necesidad salvífica de la confirmación y la unción.

Ha de notarse, en este sentido, que la cuestión de la unidad y la diferencia aparece profusamente en el pensamiento del Cusano. Tiene ella ante todo una cara metafísica y epistémica. Ya aparece al modo de la coincidentia oppositorum en De docta ignorantia: 'lo máximo absoluto inteligido incomprensiblemente; con ello coincide lo mínimo (maximum absolutum incomprehensibiliter intelligitur; cum quo minimum coincidit)' ${ }^{126}$. Años después, en la que probablemente es su última obra, De apice theoria, terminada en 1464, acontece otro tanto. El Cusano afirma allí que el poder es lo que unifica todas las cosas, aquello en

como doctrina- tiende a nivelar a la pluralidad con la unidad, incluso a privilegiarla en desmedro o en completa anulación de la unidad, como se ve en James, Marquard, Guattari y Deleuze. Este vaivén puede resumirse así: «toda la filosofía no es otra cosa que el estudio de las determinaciones (Bestimmungen) de la unidad», "el punto principal que conviene advertir es que la unidad y la multiplicidad se hallan absolutamente coordinadas. Ninguna de las dos es primordial, más esencial o más excelente que la otra», $\mathrm{y}$ "no hay unidades [...] sino únicamente multiplicidades»: Mariano Álvarez Gómez, "La pretensión ontológica del pluralismo», en Azafea. Revista de filosofía 6 (2004), 110. Son citas, respectivamente, de Hegel, Philosophie der Religion I, en Werke in zwanzig Bänden XVI (Frankfurt a. M.), 100, de JAMES, Pragmatismo (Madrid 2000), 132, y de Deleuze y Guattari, Rizoma. Introducción (Valencia 2003), 20. Nicolás de Cusa, dice Álvarez Gómez, es parte de esa tradición. La pluralidad tiene gran peso ontológico para él, sin embargo de lo cual enfatiza su esencial dependencia de la unidad. Por eso dice: cada cosa está en cada cosa, todas ellas en cada una, el universo en cada cosa, y Dios mismo en el universo, en todas las cosas y en cada una de ellas. Por eso afirma que la pluralidad es en la unidad, y que la unidad es en la pluralidad (cf. De docta ignorantia, h I, l. II, c. V, n. 119, p. 77, 19-20 y c. VI, n. 123, p. 79, 5-6). La idea de Álvarez Gómez es que la unidad es imprescindible, tanto para abordar las cosas en su individualidad, como para abordarlas en sus relaciones mutuas, y para tratar de los conceptos con los que nos referimos a ellas monológica o dialogalmente. Se piensa que hay cierto fetichismo en las nociones de unidad absoluta, de unidad mística y de unidad conceptual, y uno peligroso, pues sería tendencialmente represivo y aun totalitario. En contra, añade Álvarez Gómez, cabe decir que los grandes pensadores de la unidad -el Cusano uno de ellos- nunca perdieron de vista la libertad ni la pluralidad de las cosas en su infinita variedad y riqueza (cf. Álvarez Gómez, «La pretensión ontológica del pluralismo», 79-87 y 110-111).

126 Vid. De docta ignorantia, h I, 1. I, c. IV, n. 11-12. 
cuya virtud «toda diferencia desemboca en concordancia (omnem differentiam transire in concordantiam)» ${ }^{127}$. Hay también una cara eclesiástica y ecuménica de la unidad en la diferencia, la que es inundatoria en $D e$ concordantia católica. Por lo que toca a su dimensión interreligiosa, esta se destaca, más allá de DPF y de la carta a Juan de Segovia, en el primer capítulo del Idiota. De mente, cuando el filósofo, antes de que entre en escena el ignorante (idiota) que va a conducir toda la conversación, se declara admirado y dice: "pues viendo transitar con gran apresuramiento innumerables multitudes, que provienen de casi todos los climas, admiro la fe de todos, que es una dentro de tanta diversidad de cuerpos (fidem unam in tanta corporum diversitate). Pues dado que ninguno es semejante al otro, sin embargo, la fe de todos es una (una tamen omnium fides est), la cual los condujo con tanta devoción desde los confines de la tierra» ${ }^{128}$.

Especial atención necesitaría la dimensión intelectual de la unidad y la diferencia. La inteligencia filosófica y teológica se mueve entre la unidad y la diversidad. Así, dice el Cusano, puede -y habría que agregar: debe- armonizarse a los teólogos discrepantes ${ }^{129}$. Y un capítulo del

127 Vid. De apice theoria, h XII, n. 15, 20.

128 Vid. Idiota. De mente, h V, c. I, n. 51, 18-20. Uso la trad. de J. Machetta: $N$. d. Cusa, Un ignorante discurre acerca de la mente (Idiota. De mente), (B. Aires, Biblos 2005), 39.

129 Vid. De possest, h XI/2, n. 21, 1-2. La cuestión de la unidad inefable de Dios y sus muchas denominaciones posibles tanto históricas como incluso especulativas muestra la dialéctica entre lo uno y lo múltiple. En el sermo de 1428-30 In principio erat Verbum, el intelecto humano no tiene una visión intrínseca del Dios uno y simple. Todos los nombres divinos son inadecuados (salvo el inefable Tetragrama), pero, sin embargo, convergen en la verdad una y simple. Después, en el sermo de 1439-40 Nomen eius Iesus, aparece junto al Tetragrama el otro nombre inefable: Jesús. Los 3 caminos para nombrar a Dios son el que va de lo imperfecto a lo perfecto, el eminencial y el de la remoción o negación, siendo claro esta via negativa o de la remoción la privilegiada. En gral., son muchos los nombres enigmáticos de Dios, del principio primero, a los que Nicolás va recurriendo durante el curso de su obra: mismo mismo (ipsum idem) (cf. De docta ignorantia h I, l. I, c. IX, n. 25, De genesi, h IV, c. I, n. 142-143), poder es (possest) (cf. Possest), no otro (non aliud) (cf. De li non-aliud), poder mismo (posse ipsum) (cf. Compendium, De apice theoriae). Para todas estas referencias, vid. J. González, «1.2. La fuerza significativa de lo "no-otro"", en N. de Cusa, Acerca de lo no-otro o de la definición que todo define, J. Machetta (trad.) (B. Aires, Biblos 2008), 247-258. Cabe agregar que en De docta ignorantia se establece que no hay ningún nombre de Dios adecuado. Si Dios 
Idiota. De mente, a mayor abundamiento, se titula "cómo se entienden y concuerdan los filósofos (quomodo intelligantur et concordentur philosophi) ${ }^{130}$. Mas este no es asunto solo de la mentalidad filosófica y teológica. Todo ejercicio de la inteligencia realiza la coincidentia oppositorum. Según Nicolás, en efecto, «el hombre no puede juzgar más que humanamente (homo non potest iudicare nisi humaniter). Cuando, en efecto, el hombre te atribuye un rostro, no lo busca fuera de la especie humana, pues su juicio está contraído al ámbito de la naturaleza humana y al juzgar no escapa a la afección de esta contracción. Igualmente, si un león te atribuyese un rostro, consideraría que no puede ser sino semejante a un león, y un buey de modo bovino y el águila el de un águila» ${ }^{131}$.

3.4. Por otra parte, aquí no he referido más que algunas recientes lecturas de DPF. La Wirkungsgeschichte de este libro, así como de la filosofía del Cusano, es inmensa. Este es un autor difícilmente comprensible sin filosofías anteriores como, entre otras, las de Platón, Aristóteles, Orígenes, Proclo, Agustín, el Pseudo Dionisio, Escoto Eriúgena, Tomás de Aquino, Ramon Llull, el Maestro Eckhart, incluso sin las próximas de Marsilio Ficino y Pico della Mirandola, y cuya datación -básicamente medieval o ya germinalmente moderna- es discutida ${ }^{132}$.

está por sobre todo intelecto, con mayor razón está sobre todo nombre. Dios es inefable; hebreos, caldeos, paganos nombran a Dios por referencia a las creaturas. De ahí la necesidad de la teología negativa (cf. De docta ignorantia, h I, l. I, c. XXIV-XXVI).

130 Vid. Idiota. De mente h V, c. III.

131 De visione dei, h VI, c. VI, n. 19, p. 21, 15-22. Uso esta versión castellana: N. D. Cusa, La visión de Dios, A. L. González (trad.) (Pamplona, EUNSA 52007), 7980. Claro es que esto se relaciona con el perspectivismo y la conjeturalidad: cf. al respecto de nuevo E. Solari, «Contornos de la tolerancia medieval» [inédito].

132 Para un panorama sobre el talante medieval o protomoderno del Cusano, vid. también E. Colomer, «Nicolás de Cusa, un pensador en la frontera de dos mundos", en De la Edad media al Renacimiento. Ramón Llull - Nicolás de Cusa Juan Pico Della Mirandola (Barcelona, Herder 1975), 119-144; R. Hüntelmann, «El Cusano y la primera filosofía moderna de la creación», en Anuario filosófico 28 (1995), 649-670, y D. Moran, "Nicholas of Cusa (1401-1464): Platonism at the Dawn of Modernity», en D. Hedley y S. Hutton (eds.), Platonism at the origins of modernity: studies on Platonism and early modern Philosophy (Dordrecht, Springer 2008), 9-12. El asunto, tan discutible, es bien argumentado por J. Hopkins, según el cual el Cusano no es el primer filósofo moderno: J. Hopkins «Nicholas of Cusa (1401-1464): First Modern Philosopher?», en Midwest Studies in Philosophy 26 (2002), 13-29. 
Sobre la larga la historia de la recepción de DPF, dicho sea de paso, Klibansky ha escrito páginas estupendas ${ }^{133}$. El Cusano, dice, participa de la añosa tradición de la tolerancia, esa que ya se inicia cuando se reclama libertad religiosa desde el tiempo de las persecuciones, y que prosigue con Tertuliano, Símaco, Casiodoro, la poesía alemana del siglo XII, Tomás de Aquino ${ }^{134}$. Después de Nicolás, claro, la tolerancia empieza a adquirir sus caracteres modernos, como lo muestra casi inmediatamente Marsilio Ficino ${ }^{135}$. Klibansky también destaca el posible (incluso probable) influjo de DPF en Moro, sin por ello ocultar las diferencias entre ambos ${ }^{136}$. Añade, de nuevo pese a las diferencias, que con seguridad Bodin y Descartes conocieron al Cusano ${ }^{137}$. No hay, en cambio, ni una palabra sobre el Cusano en Schelling y Hegel ${ }^{138}$. Mas enseguida, sobre todo a partir de Lessing (y otra vez pese a las diferencias entre ambos), el carácter inspirador de DPF se volverá masivo ${ }^{139}$.

3.5. Aquella mención del Mirandolano, en todo caso, no era gratuita. La oratio de hominis dignitate prolonga el aliento de DPF. Como se sabe, para esa suerte de manifiesto renacentista de Pico della Mirandola la dignidad humana radica en la libertad: "¿quién no admirará a este nuestro camaleón (quis hunc nostrum chamaeleonta non admiretur)?" 140 . Justo por ser libre, dice Pico, el hombre no tiene una naturaleza definida (definita natura) como los demás seres finitos, sino que debe procurársela o, si se quiere, determinarla por su propio arbitrio:

133 Raymond Klibansky, "Die Wirkungsgeschichte des Dialogs "De pace fidei"», en MFCG 16 (1984),113-125.

134 KLIBansky, reenvía a la STh II-II, q.10.

135 Klibansky, «Wirkungsgeschichte», 116-117. Cf. el cap. 4 de De christiana religione, de 1474 .

136 KLIbansky, «Wirkungsgeschichte», 118-119.

137 Klibansky, «Wirkungsgeschichte», 119.

138 Klibansky, «Wirkungsgeschichte», 120.

139 Klibansky, «Wirkungsgeschichte», 122-125.

140 Vid. $\$ 7.32$ (trad. esp., p. 209). Para el original latino, vid. el sitio de la Universidad de Brown: http://www.brown.edu/Departments/Italian_Studies/ pico/text/ov.html. Para la traducción castellana, me baso en Giovanni Pico della Mirandola, Discurso sobre la dignidad del hombre. Una nueva concepción de la filosofía, S. Magnavacca (trad.) (B. Aires, Winograd 2008), 202-279. 
«no te hice ni celeste ni terreno, ni mortal ni inmortal, con el fin de que, como árbitro y soberano artífice de ti mismo, te plasmes y cinceles en la forma que tú prefieras (nec te caelestem neque terrenum, neque mortalem neque immortalem fecimus, ut tui ipsius quasi arbitrarius honorariusque plastes et fictor, in quam malueris tu te formam effingas) 》" ${ }^{141}$.

El hombre es el que puede ser «aquello que quiera (id esse quod velit) ${ }^{142}$. Aún más. Hay que agregar que la oratio parte de la libertad, prosigue con la filosofía e intenta así franquear el acceso a la paz. La filosofía es, como en el querubín, el «esplendor de la inteligencia (intelligentiae splendore)» ${ }^{143}$. Justamente la contemplación y la meditación hacen que resplandezca en el hombre esa «luz querubínica (luce Cherubica)» ${ }^{144}$. Y la paz, concordia interna y externa, "paz santísima», "amistad unánime», la «seguridad de una paz perpetua (perpetuae pacis securitas)», es, según el Mirandolano, aquello a lo que conducen la libertad y la filosofía (y que es justamente lo que el Sumo Dios quiere por sobre todas las cosas $)^{145}$.

A la luz de Pico, en efecto, se aprecia que el Cusano tiene ya algo de renacentista. Precisamente, podría decirse que la modernidad de Nicolás radica en su incipiente apología de la libertad. La paz de la fe remite a la libertad, en la medida en que la paz es producto de un diálogo en el que participan las naciones y los cultos. El mismo ignorante (idiota) que protagoniza los diálogos del Cusano es un hombre libre: libre de la arrogancia libresca de los sabios y libre de copiar la naturaleza, así como es libre para medir y pensar a partir de las cosas y libre (de manera análoga al artesano que fabrica cucharas) para crear nuevos objetos. Se aprecia en esta configuración de la libertad, y sin despreciar por ello sus rasgos teológicos y medievales, una defensa tendencialmente hodierna del individuo ${ }^{146}$. La voluntad libre (libera voluntas), ha dicho el Cusano en De visione dei, es viva imagen de la fuerza de la omnipotencia de Dios ${ }^{147}$.

${ }^{141}$ Vid. $\$ 5.22$ (trad. esp., p. 207).

${ }_{142}$ Vid. $\$ 6.25$ (trad. esp., p. 209).

143 Vid. $\$ 11.57$ (trad. esp., p. 215).

144 Vid. $\$ 11.59$ (trad. esp., p. 215).

145 Cf. $\$ 16.88$ - $\$ 18.103$ (trad. esp., pp. 220-225). Vid. S. Magnavacca, «Estudio preliminar, en Giovanni Pico della Mirandola, Discurso, 12 y en gral. 19-182.

146 Cf. Idiota. De sapientia, h V, n. 1-4, e Idiota. De mente, h V, n. 54-55.

147 Cf. De visione dei, h VI, c. IV, n. 11, p. 15, 2-4. 
Aún más: es significativo que en esa misma obra Dios le diga a Nicolás: "sé tú tuyo y yo seré tuyo (Sis tu tuus et ego ero tuus)», y que el hombre le responda congruentemente:

«oh, Señor, suavidad de toda dulzura, pusiste en mi libertad (in libertate mea) que sea, si lo quiero, mío (mei ipsius = de mí mismo). De aquí que si yo no soy mío, tú tampoco eres mío; pues forzarías la libertad, ya que tú no podrías ser mío si yo no fuera a la vez mío. Y, porque pusiste esto en mi libertad, no me fuerzas, sino que me esperas, para que yo elija ser mío (ut ego eligam mei ipsius esse)» ${ }^{148}$.

3.6. Tanto esta defensa de la libertad entendida como autoposesión, como la que hace Pico de la libertad en cuanto capacidad de autodeterminación, han sido objeto de juicios contrastantes. Ciertos filósofos naturalistas han visto en ellas una negación de la naturaleza humana ${ }^{149}$. Otros, en cambio, han defendido la idea según la cual la indeterminación natural del hombre no equivale a la inexistencia de una naturaleza humana, sino más bien a la presencia en el hombre de una doble naturaleza: una, la biológica, fija y ya constituida, y otra, la moral, plástica y adquirida a través de los propios actos libres a lo largo de la vida ${ }^{150}$. Esta es, dicho sea de paso, una nueva versión de la diferencia griega entre $\zeta \omega \eta ́$ y ßíos. Sea de ello lo que fuere, es un asunto de enorme interés filosófico. $\mathrm{Y}$ es que, en efecto, conviene estudiar al Cusano no solo historiográficamente, como puro asunto textual para medievalistas, sino también de manera especulativa, vale decir, por las cuestiones rigurosamente filosóficas que este pensador ha planteado y elaborado.

148 Cf. De visione dei, h VI, c. VII, n. 25, p. 27, 15-19. Uso aquí, con algunas modificaciones, la traducción de F. Bastitta: «La filosofía de la libertad en Nicolás de Cusa y en la Academia florentina y las huellas del pensamiento patrístico», en Forum 3 (2008), 76. Este decisivo matiz, que sea el hombre «suyo» (o "de sí mismo») para que Dios también pueda ser «suyo» (= del hombre), es el que se pierde en la traducción de A. L. GonzÁlez: «oh, Señor, suavidad de toda dulzura, has puesto en mi libertad que, si yo lo quiero, yo sea yo mismo. Por tanto, si yo no soy yo mismo, tú no eres mío; de otro modo coartarías mi libertad, ya que tú puedes ser mío únicamente cuando yo sea yo mismo. Pero como has establecido esto en mi libertad, no me coartas, sino que esperas que yo escoja ser yo mismo» (N. D. CusA, La visión de Dios, A. L. González (trad.), 84)

149 Cf. Por ej. J. Mosterín, La naturaleza humana (Madrid Espasa 2006), 17-18.

150 Cf. Las reflexiones al respecto que, vinculando al Cusano con Pico y en gral. con el renacimiento, ha hecho L. Villoro, El pensamiento moderno. Filosofía del Renacimiento (México, FCE 2010), 35-39 y 45-46. 
Desde esta última perspectiva, la idea cusana de que el hombre puede y tiene que ser «suyo» (vinculada con la piquiana de que para serlo ha de optar entre posibilidades que configurarán en uno u otro sentido su básica, carente y abierta naturaleza), ha dado mucho de sí. Últimamente Zubiri la ha recogido y profundizado en sus propios términos:

«al hacer su vida, el hombre entre las posibilidades que tiene elige unas $y$ rechaza otras, de modo que la figura que el hombre determina en cada acto vital suyo pende en gran parte de decisiones suyas. La necesidad que el hombre tiene de 'apropiarse' unas posibilidades en lugar de otras, hacen de él una realidad peculiar. En efecto, además de las propiedades formales que emergen 'naturalmente' de las sustancias que la componen, la sustantividad humana tiene otras cuya raíz no es una 'emergencia' sino una "apropiación": la apropiación de posibilidades. En tal caso, el momento subjetual de la realidad humana cobra un carácter singular. Por un lado, esa realidad es, como cualquier sustancia, sujeto de las propiedades que posee por razón de las sustancias que la componen. Pero por otro, no está "por-bajo-de" sus propiedades, sino justamente al revés, está "por-encima-de" ellas, puesto que se las apropia por aceptación. En su virtud, yo diría que en este aspecto no es hýpo-keímenon, sino más bien hýper-keímenon, algo no solo sub-stante, sino también supra-stante» ${ }^{151}$.

He aquí una nueva versión del mismo problema filosófico: la naturaleza en que el hombre consiste es algo que depende, al menos parcialmente, de sus propios actos libres. No se crea que para Zubiri el hombre no tiene esencia o naturaleza, pero sí que -a su manera de ver- la humana es una esencia abierta, vale decir, una que no es solo res naturalis sino también res eventualis ${ }^{152}$. Esto significa que por sus actos el hombre va conquistando una figura y caracterizando su propia personalidad, su forma de ser real. Dice Zubiri: en cada uno de sus actos el hombre se apropia unas determinadas posibilidades y, así, actúa siempre y en todo caso en vistas de su propia realidad. Por ello es persona, es esa peculiar realidad que posee formaliter su propia realidad:

«y es que efectivamente la realidad humana es para mí mismo no solo un simple sistema de notas que "de suyo" me constituyen, sino que es ante todo y sobre todo la realidad que me es propia en cuanto realidad, es decir es mi realidad, mi propia realidad. Y en su virtud soy una reali-

151 Zubiri, Sobre el hombre (Madrid, Alianza 1986), 343.

152 Vid. Zubiri, Sobre la esencia (Madrid, Alianza $\left.{ }^{2} 2008\right)$, 4-5 y 515-517. 
dad que, como forma de realidad, no solamente soy "de suyo" (en esto coincido con todas las demás realidades), sino que además soy "mío". Tengo una realidad que es mía, cosa que no acontece a una piedra. El hombre tiene como forma de realidad esto que he llamado suidad, el ser "suyo" " 153 .

3.7. Es difícil, pues, exagerar el relieve que la libertad tiene para la paz. Solo hombres que son dueños de sí mismos resultan capaces de articular una concorde diversidad religiosa. El hombre es creado libre, según DPF, y, sin embargo, se desvía y cae en la vida sensible. Por eso Dios envía primero profetas y luego a su Hijo, que todo lo complica y por el que todo es explicado. Dios ya no puede hacer más y, así, gracias al Dios humanizado, todo hombre es capaz, con la libertad de su naturaleza, de vida eterna y, claro, de la paz, de concordia en medio de las diferencias.

DPF defiende, estrictamente hablando, que la paz es fruto de la libertad humana, y que lo es en tanto en cuanto el ejercicio de esta autoposesión es necesario para conquistar y mantener aquella pacífica convivencia interreligiosa e internacional. Como medieval que era, el Cusano también pensaba que sin el concurso divino la paz no sería posible. La suya, conviene repetirlo, es una versión medieval de la tolerancia con algunos aires modernos. Solamente ahora se puede comprender en propiedad esta afirmación inicial. La tolerancia moderna no es exactamente idéntica con la medieval, pero como el Cusano es un pensador del otoño de la edad media en el que ya surgen impulsos modernos, cabe ver en la peculiar tolerancia y convivencia no violenta de religiones y nacionalidades a que se refiere DPF una variable dependiente de la libertad. Precisamente por ella el ser humano no solo escoge unos u otros actos, sino que sobre todo se elige a sí mismo, se determina autónomamente y puede eo ipso configurar en alguna medida las (mejores o peores) condiciones de su propia convivencia y unas (mejores o peores) trayectorias históricas.

153 Zubiri, El hombre y Dios (Madrid, Alianza 1984), 48. 
Resumen: Este artículo resume las articulaciones fundamentales de De pace fidei, luego de lo cual muestra algunas de sus mejores interpretaciones recientes y plantea ciertas cuestiones que aún merece la pena explorar en aquella obra, particularmente la de su conexión con la filosofía de la libertad del Cusano y la del reflejo ya renacentista que tal filosofía halla en la oratio de Pico della Mirandola.

Palabras clave: Paz, tolerancia, religiones, cristianismo, verdad, libertad.

Abstract: This article summarizes the fundamental reasonings in De pace fidei and goes on to show some of their most relevant recent readings, to finally lay down some questions which are still worth exploring in the cited work, in particular its connection with the philosophy of freedom of the Cusanus and the reflection, with renaissance spirit, which such philosophy finds in the oratio of Pico della Mirandola.

Keywords: Peace, tolerance, religions, christianism, truth, freedom. 